\title{
Biosensor-aided high-throughput screening of hyper-producing cells for malonyl-CoA-derived products
}

Heng Li ${ }^{1,3}$, Wei Chen ${ }^{1}$, Ruinan Jin ${ }^{1}$, Jian-Ming Jin ${ }^{2^{*}}$ and Shuang-Yan Tang ${ }^{1^{*}}$ (D)

\begin{abstract}
Background: Malonyl-coenzyme A (COA) is an important biosynthetic precursor in vivo. Although Escherichia coli is a useful organism for biosynthetic applications, its malonyl-CoA level is too low.

Results: To identify strains with the best potential for enhanced malonyl-CoA production, we developed a whole-cell biosensor for rapidly reporting intracellular malonyl-CoA concentrations. The biosensor was successfully applied as a high-throughput screening tool for identifying targets at a genome-wide scale that could be critical for improving the malonyl-CoA biosynthesis in vivo. The mutant strains selected synthesized significantly higher titers of the type III polyketide triacetic acid lactone (TAL), phloroglucinol, and free fatty acids compared to the wild-type strain, using malonyl-CoA as a precursor.
\end{abstract}

Conclusion: These results validated this novel whole-cell biosensor as a rapid and sensitive malonyl-CoA highthroughput screening tool. Further analysis of the mutant strains showed that the iron ion concentration is closely related to the intracellular malonyl-CoA biosynthesis.

Keywords: Whole-cell biosensor, Malonyl-CoA, High-throughput screening, Triacetic acid lactone, Phloroglucinol

\section{Background}

Malonyl-coenzyme (CoA) is an essential building block for the biosynthesis of natural products, including fatty acids, polyketides, stilbenes and flavonoids, by providing the two-carbon units. Many of these compounds show beneficial properties for medical applications, including anti-cancer, anti-bacterial, antiviral, anti-inflammatory and anti-allergic activities, as well as in the development of agricultural products (e.g., insecticides) [1-5]. Several recent studies have reported the biosynthesis of these compounds in Escherichia coli [6-8]. Indeed, E. coli has become a widely used host for the industrial production of chemicals and fuels given that its genetic background

\footnotetext{
*Correspondence: jinjianming@btbu.edu.cn; tangsy@im.ac.cn ${ }^{1}$ CAS Key Laboratory of Microbial Physiological and Metabolic Engineering, State Key Laboratory of Microbial Resources, Institute of Microbiology, Chinese Academy of Sciences, Beijing, China

${ }^{2}$ Beijing Key Laboratory of Plant Resources Research and Development, Beijing Technology and Business University, Beijing, China

Full list of author information is available at the end of the article
}

has been extensively studied and molecular manipulation techniques with this bacterium are highly developed. However, since the intracellular malonyl-CoA level in E. coli is only around $0.07 \mathrm{nmol} / \mathrm{mg}$ dry cell weight [9], enhancement is needed for it to be effectively employed in specific biosynthesis applications.

To this end, metabolic engineering strategies to elevate the intracellular malonyl-CoA biosynthesis in $E$. coli have been reported (Fig. 1). The main carbon flow from pyruvate and acetyl-CoA flows into the tricarboxylic acid (TCA) cycle, and only a small portion transforms into malonyl-CoA which participates in fatty acid biosynthesis [10]. In addition, pyruvate and acetyl-CoA are shunted to lactate and acetate respectively. AcetylCoA carboxylase (ACC) is proposed to be a major ratecontrolling enzyme for malonyl-CoA biosynthesis [11]. ACC catalyzes the first committed step of the fatty acid synthetic pathway, and its overexpression proved to be effective to increase both the intracellular level of malonyl-CoA and the rate of fatty acid synthesis [12]. Based 


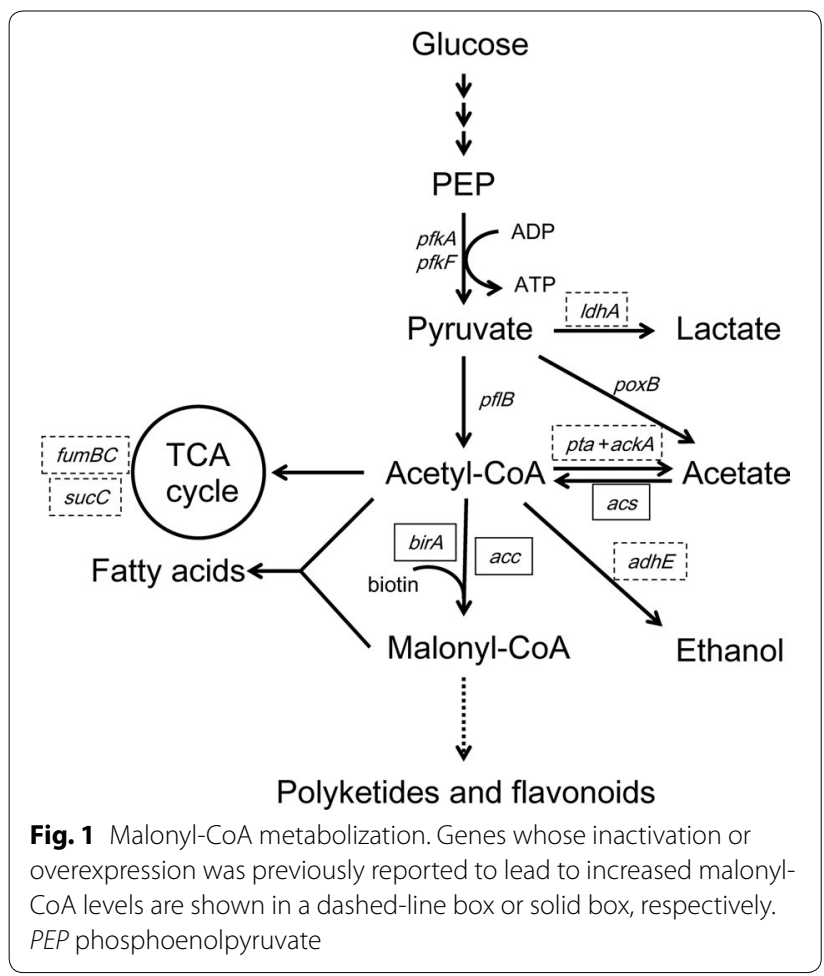

on ACC overexpression, FadA and FadB were also overexpressed to further increase the content of free fatty acids [13]. In addition to ACC, Rathnasingh et al. overexpressed the biotinilase BirA to active AccB, a subunit of ACC, by providing biotin [14]. Moreover, the lactate and acetate branching pathways can be blocked by deletion of the lactate dehydrogenase (ldhA), phosphotransacetylase (pta) [15] and acetate kinase (ackA) genes. Zha et al. reported that deletion of a second competing pathway $(\triangle a d h E)$ that produces byproduct ethanol from acetylCoA also led to a slightly greater increase of the cellular malonyl-CoA concentration [9]. They further proved that the dual manipulation of acetate production from acetylCoA, involving assimilation [acetyl-CoA synthetase (Acs) overexpression] and pathway knockout ( $\Delta p t a \Delta a c k A)$, showed a synergistic effect in combination with ACC overexpression, resulting in a 15 -fold improvement in the intracellular level of malonyl-CoA compared with that detected in wild type E. coli. Although some genes playing an important role in mediating the intracellular malonyl-CoA level have been identified through rational design strategies, a high-throughput genome-wide screen for genes that affect the metabolic flux flowing to malonyl-CoA has not yet been attempted because of the lack of appropriate screening tools.

Malonyl-CoA is usually quantified by liquid chromatography-mass spectrometry (LC-MS) [16]. In the present study, we aimed to develop a high-throughput screening tool to facilitate a genome-wide screen of targets influencing the intracellular malonyl-CoA biosynthesis. In brief, a whole-cell biosensor for malonyl-CoA was developed based on a mutated AraC regulatory protein that is responsive to triacetic acid lactone (TAL) [17]. We then validated the whole-cell biosensor as a screening tool for rapidly and sensitively selecting $E$. coli strains showing hyper-production of malonyl-CoA from a random transposon insertion library (Fig. 2a). Use of this system is expected to provide novel gene targets related to the intracellular malonyl-CoA biosynthesis, and thus extend the biosynthetic applications of E. coli.

\section{Results \\ Design and validation of a whole-cell biosensor of malonyl-CoA}

To effectively monitor the malonyl-CoA biosynthesis in E. coli, a malonyl-CoA whole-cell biosensor was developed based on a mutated transcriptional regulatory protein $\mathrm{AraC}$ that is responsive to TAL (AraC-TAL) [17]. The mutated protein, AraC-TAL, was previously reported to regulate the expression of the $l a c Z$ gene controlled by the $\mathrm{P}_{\mathrm{BAD}}$ promoter in a TAL concentration-dependent manner. Here, we used the heterologous expressed 2-pyrone synthase (2-PS) mutant S1 [17] to produce TAL using malonyl-CoA as a substrate. Therefore, the intracellular malonyl-CoA level was reflected by the TAL concentration, which can be rapidly reported according to the measurement of LacZ activity (Fig. 2a). Thus, the wholecell biosensor of malonyl-CoA constructed by combining the AraC-TAL regulatory system and the 2-PS variant S1 can be used for in vivo high-throughput screening of malonyl-CoA.

To evaluate the validity of the high-throughput screening method, we treated the E. coli strain with triclosan, which is a broad-spectrum antibacterial and antifungal agent that blocks lipid synthesis in E. coli [18]. Specifically, triclosan inhibits the incorporation of malonyl-CoA into the cellular free fatty acid synthesis by inhibiting $\mathrm{FabI}$ activity [19]. Due to the reduction in fatty acid synthesis, its precursor malonyl-CoA could accumulate. Thus, strains treated with different concentrations of triclosan were expected to exhibit different intracellular malonylCoA biosynthetic capabilities, resulting in different TAL production levels (Fig. 2b). As expected, in the triclosan concentration range of $0.1-0.5 \mathrm{mg} / \mathrm{L}$, the TAL titers increased from 7.3 to $26.6 \mathrm{mg} / \mathrm{L}$ (Fig. 2b). There was also a good linear correlation detected between the triclosan concentration and the LacZ activity under $0-0.3 \mathrm{mg} / \mathrm{L}$ triclosan, confirming that the LacZ activity can be used to report the intracellular malonyl-CoA biosynthesis in this range (Fig. 2b). 

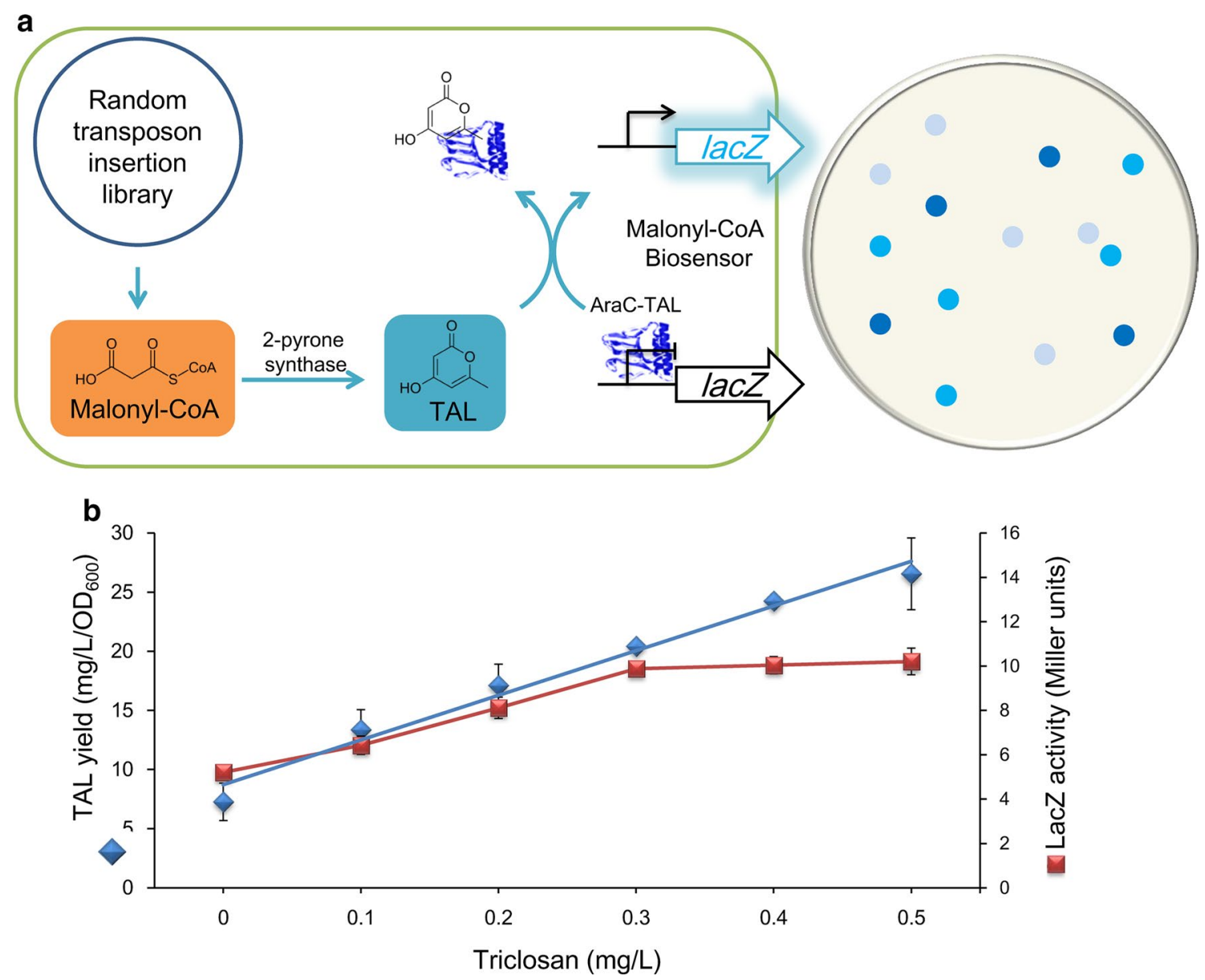

Fig. 2 a Schematic diagram of the whole-cell biosensor of malonyl-CoA as a high-throughput screening tool. b Positive correlation between intracellular malonyl-CoA concentration (adjusted by triclosan) and TAL yield or LacZ activity (linear correlation coefficient $=0.9933$ from 0 to $0.3 \mathrm{mg} / \mathrm{L}$ triclosan)

\section{Genome-wide screening for targets related to the intracellular malonyl-CoA biosynthesis}

To rapidly identify the target genes whose inactivation could improve the intracellular malonyl-CoA biosynthesis at a whole-genome scale, a transposon insertion library was constructed in strain BW-WT (with wild-type araC deleted and the $\mathrm{P}_{\mathrm{BAD}}$-lac $Z$ construct integrated). The plasmid pS1 expressing the 2-PS variant S1 and AraC-TAL was then used to transform the mutagenesis library. Certain gene disruptions influencing the malonyl-CoA biosynthesis could be reflected by measurement of the LacZ activity. Thus, mutant strains with a high intracellular malonyl-CoA biosynthetic capability could be obtained by simply selecting the bluest clones on LB agar supplemented with 5-bromo-4-chloro-3-indolyl $\beta$-D-galactopyranoside (X-GAL). Since the LacZ activity will saturate under relatively high malonyl-CoA concentrations (Fig. 2b), the mutant strains with high efficiency for malonyl-CoA synthesis could be selected at an early stage of cell growth on LB agar.

After culturing the transposon insertion library containing $\sim 2 \times 10^{5}$ mutant strains on LB agar supplemented with X-GAL for $18 \mathrm{~h}$, four of the darkest blue clones (detected by naked eye) were selected and rescreened in liquid cultures to quantify TAL production (Additional file 1: Figure S1). These clones produced 1.4-3.0-fold more TAL than those produced by strain BW-WT (Fig. 3a). The locations of the transposon insertions in the selected mutant strains were identified. The four target genes inactivated by the transposons, $\operatorname{rcs} A$, fhu $A, \operatorname{csg} A$ and $\operatorname{ton} B$ were individually knocked out in strain BW25113, resulting in strains $\Delta \operatorname{rcs} A, \triangle f h u A$, 


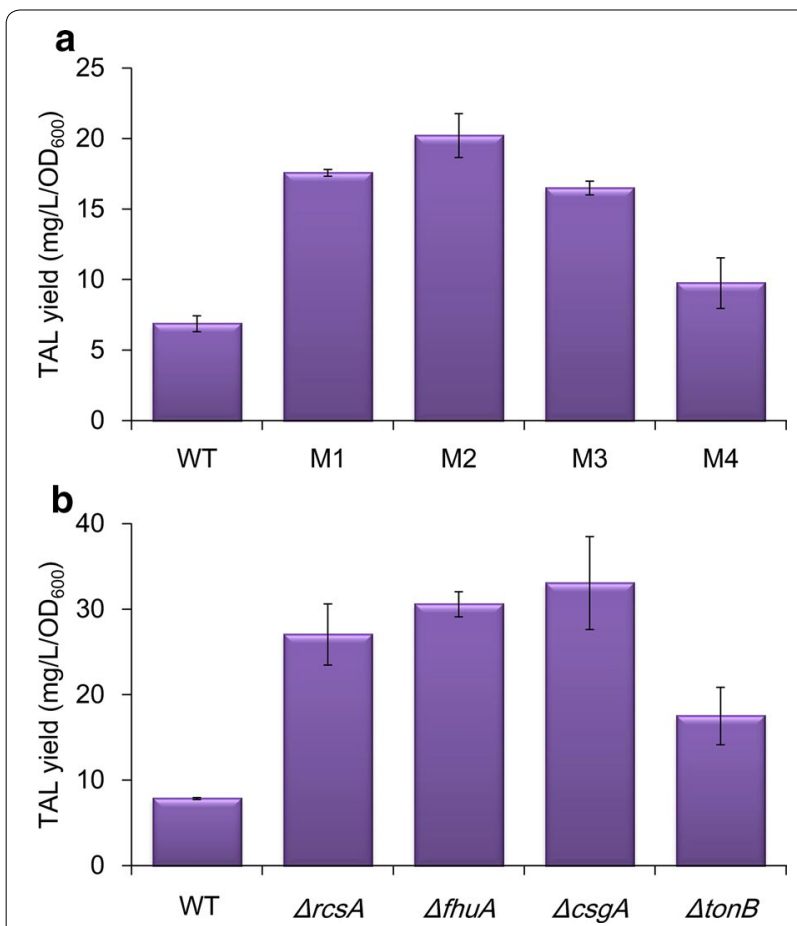

Fig. 3 a TAL yields of mutant strains selected from the random transposon insertion library. $P<0.01$. b TAL yields of mutant strains with the indicated genes deleted. $P<0.05$

$\triangle \operatorname{csg} A$, and $\triangle \operatorname{ton} B$, respectively, and the enhanced TAL formation was confirmed in the deletion mutant strains (Fig. 3b). The TAL production levels in the deletion strains were 2.2-4.2-fold higher than that in the wildtype BW25113 strain.

\section{Iron ion concentration influences the intracellular} malonyl-CoA biosynthesis

Fhu A and TonB are both involved in the formation of the ferrichrome outer membrane transport complex. FhuA is an outer membrane porin that plays a role in the transport of ferrichrome across the outer membrane [20]. Conformational changes in the outer exposed-surface loops of FhuA brought about by TonB then promote the movement of siderophore-iron complexes across the outer membrane into the periplasm [21]. Thus, FruA and TonB both take part in the absorption of iron in $E$. coli. Accordingly, disruptions of the $f h u A$ and ton $B$ genes could improve the intracellular malonyl-CoA biosynthesis, which implies that iron concentration has an influence on the intracellular malonyl-CoA biosynthesis.

To further explore the relationship between the intracellular malonyl-CoA biosynthesis and iron concentration, an iron chelator, diethylene triaminepentaacetic acid (DTPA), was used to sequester the extracellular iron of the wild-type BW25113 strain [22]. As expected, iron starvation promoted the TAL formation to a level exceeding that produced by the $\triangle f h u A$ strain, although cell growth was inhibited with DTPA treatment (Fig. 4). When the iron ion was supplemented in the medium of strain $\triangle f h u A$, TAL production was reduced with increasing iron concentrations, and the production level was almost non-detectable in the presence of $9 \mathrm{mM}$ of iron ions (Fig. 4).

\section{Production of phloroglucinol and fatty acids in the mutant strains}

To confirm the elevated intracellular malonyl-CoA biosynthetic capabilities in the selected mutant strains,

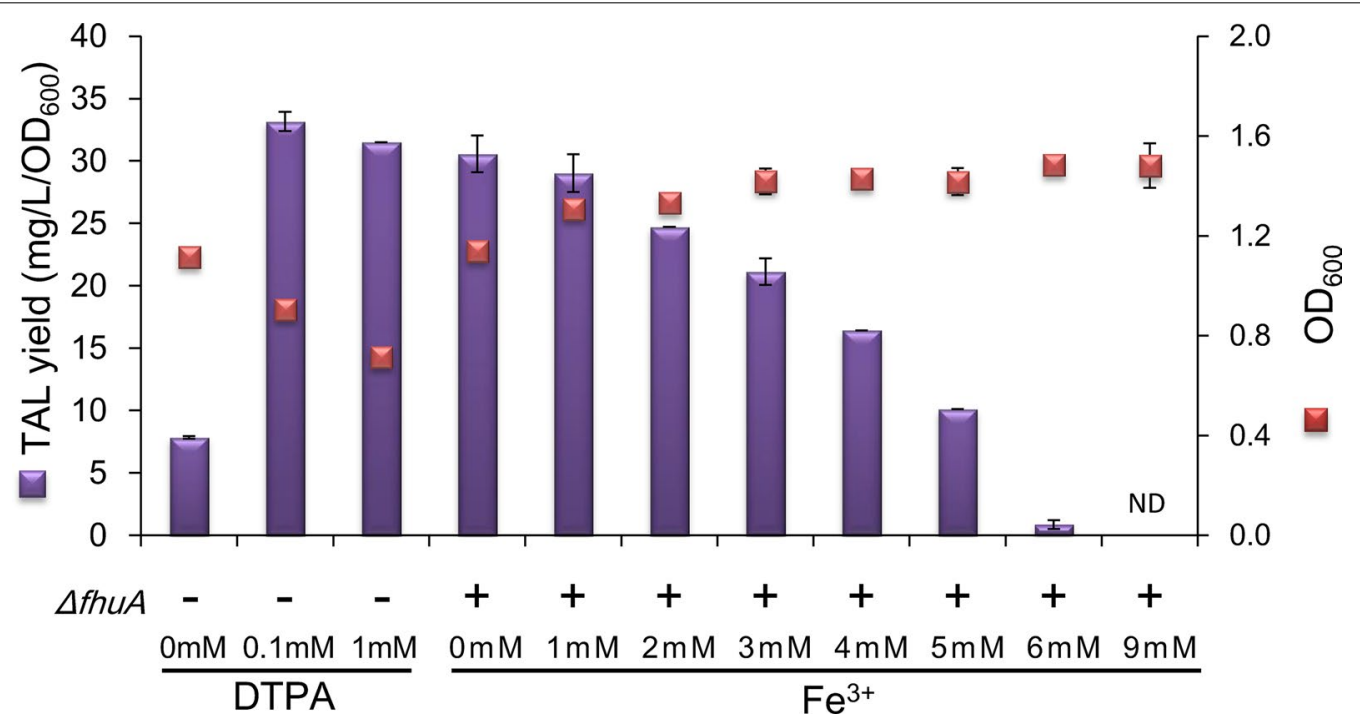

Fig. 4 TAL yields and cell growth of the wild-type strain treated with DTPA and the $\triangle$ fhuA strain treated with iron ions. $P<0.01$ 
another type III polyketide synthase from Pseudomonas fluorescens, phloroglucinol synthetase PhlD, was introduced into the $\triangle f h u A$ and $\triangle c s g A$ strains. PhlD catalyzes the biosynthesis of phloroglucinol via condensation of three molecules of malonyl-CoA [23]. As shown in Fig. 5a, the phloroglucinol yields in the $\triangle f h u A$ and $\triangle c s g A$ strains increased by 40 and $80 \%$, respectively, compared with that in the wild-type strain. Given that malonyl$\mathrm{CoA}$ is the sole precursor for phloroglucinol synthesis, the improved phloroglucinol production in these mutant strains confirmed their elevated intracellular malonylCoA biosynthesis.

Since malonyl-CoA is also the precursor of fatty acid biosynthesis in vivo, we determined the total free fatty acids contents in the mutant strains (Fig. 6). The results showed that the total free fatty acid levels in the $\Delta f h u A$ and $\triangle \operatorname{csg} A$ strains increased by 47 and $51 \%$, respectively,

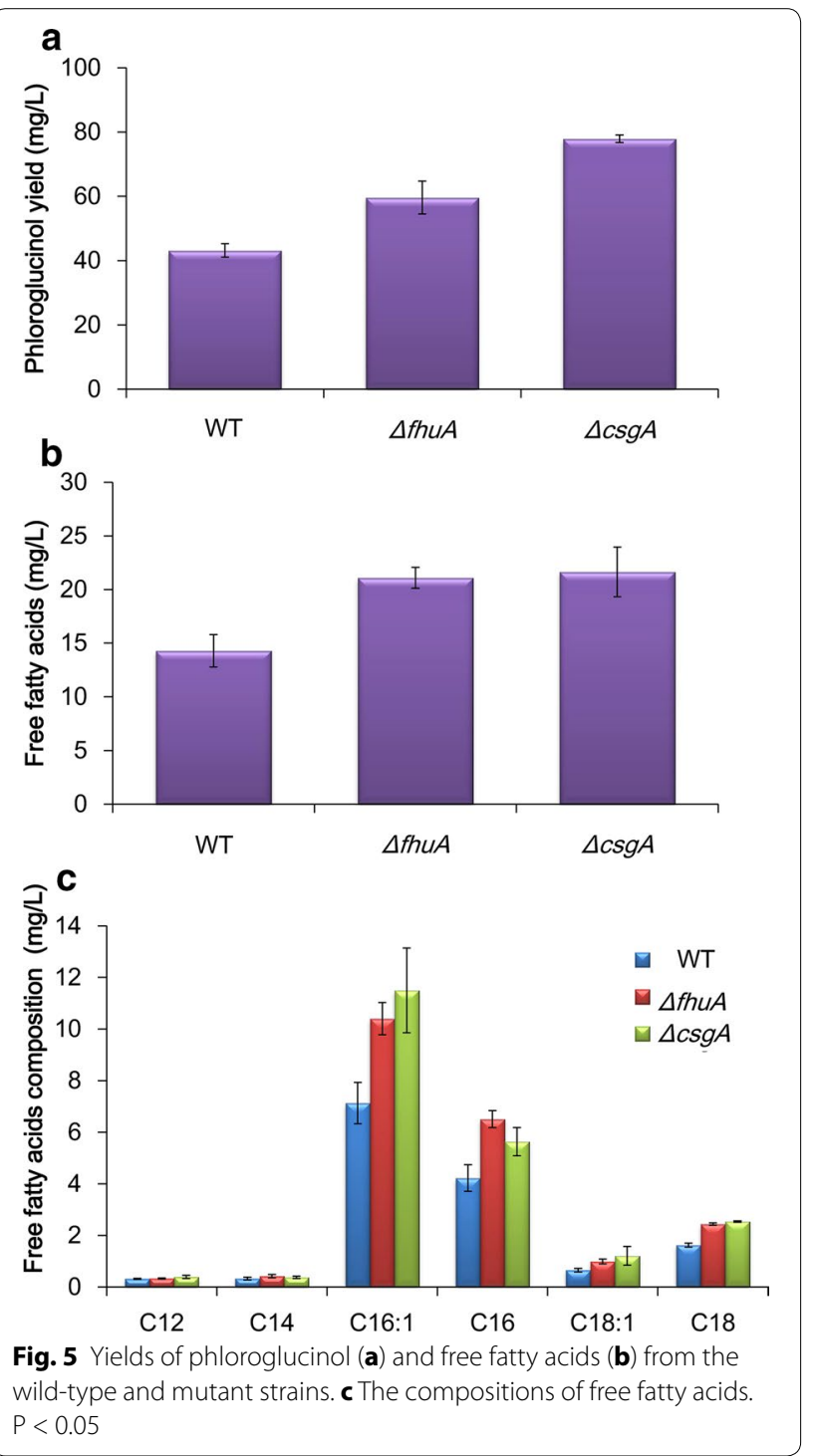

as compared with that in wild-type BW25113 (Fig. 5b). The free fatty acid compositions are shown in Fig. 5c. C16:1 and C16 straight chain fatty acids were the main free fatty acid components identified, which accounted for $\sim 80 \%$ of the total free fatty acids. The distribution of the free fatty acids composition of the mutant strains $\triangle f h u A$ and $\triangle \operatorname{csg} A$ displayed a similar pattern to that of the wild-type strain.

\section{Discussion}

A whole-cell biosensor of malonyl-CoA was developed in this study, making use of the TAL-responsive AraC regulatory protein mutant AraC-TAL. Using the biosensor as a high-throughput screening tool, mutant strains with improved malonyl-CoA biosynthetic capabilities were successfully selected from a transposon insertion mutagenesis library. Further investigation of the selected beneficial strains demonstrated that iron concentration is critical for the intracellular malonyl-CoA biosynthesis, which is a novel finding of this study. It is possible that the TCA cycle becomes inhibited in the presence of an extremely low level of iron given that several enzymes in this cycle are iron-sulfur $(\mathrm{Fe} / \mathrm{S})$ proteins [24-28], which directed more acetyl-CoA to form malonyl-CoA (Fig. 6).

RcsA is a positive activator of colanic acid capsular polysaccharide synthesis, and interacts with RcsB to optimize the transcription of genes involved in the synthesis of colanic acids [29]. Therefore, it is possible that the inactivation of RcsA would weaken the biosynthesis of colanic acids, thus leading to a higher flux of glycolysis to in turn influence the malonyl-CoA biosynthesis. CsgA is the major curli subunit. However, the effect of $\operatorname{csg} A$ deletion on intracellular malonyl-CoA biosynthesis is not yet clear.

A regulatory protein directly responsive to malonylCoA, FapR, has been previously reported, which also shows potential to be used to report the intracellular malonyl-CoA concentration [30,31], or to dynamically control the biosynthetic pathways of malonyl-CoAderived products [32-35]. However, although the intracellular pool of malonyl-CoA may vary to some extent, as a metabolic intermediate, endogenously produced malonyl-CoA would be metabolized by metabolic pathways and would not accumulate to very high levels. Thus, FapR, which directly senses the intracellular malonylCoA concentration, may not be appropriate to report the total capability of a cell for synthesizing malonyl-CoA. Using the novel biosensor developed in this study, malonyl-CoA was converted to a stable and non-metabolized product, TAL, whose concentration can be used to estimate the amount of malonyl-CoA produced by the cell during a certain period of time. Therefore, this biosensor is expected to more effectively select strains capable of 


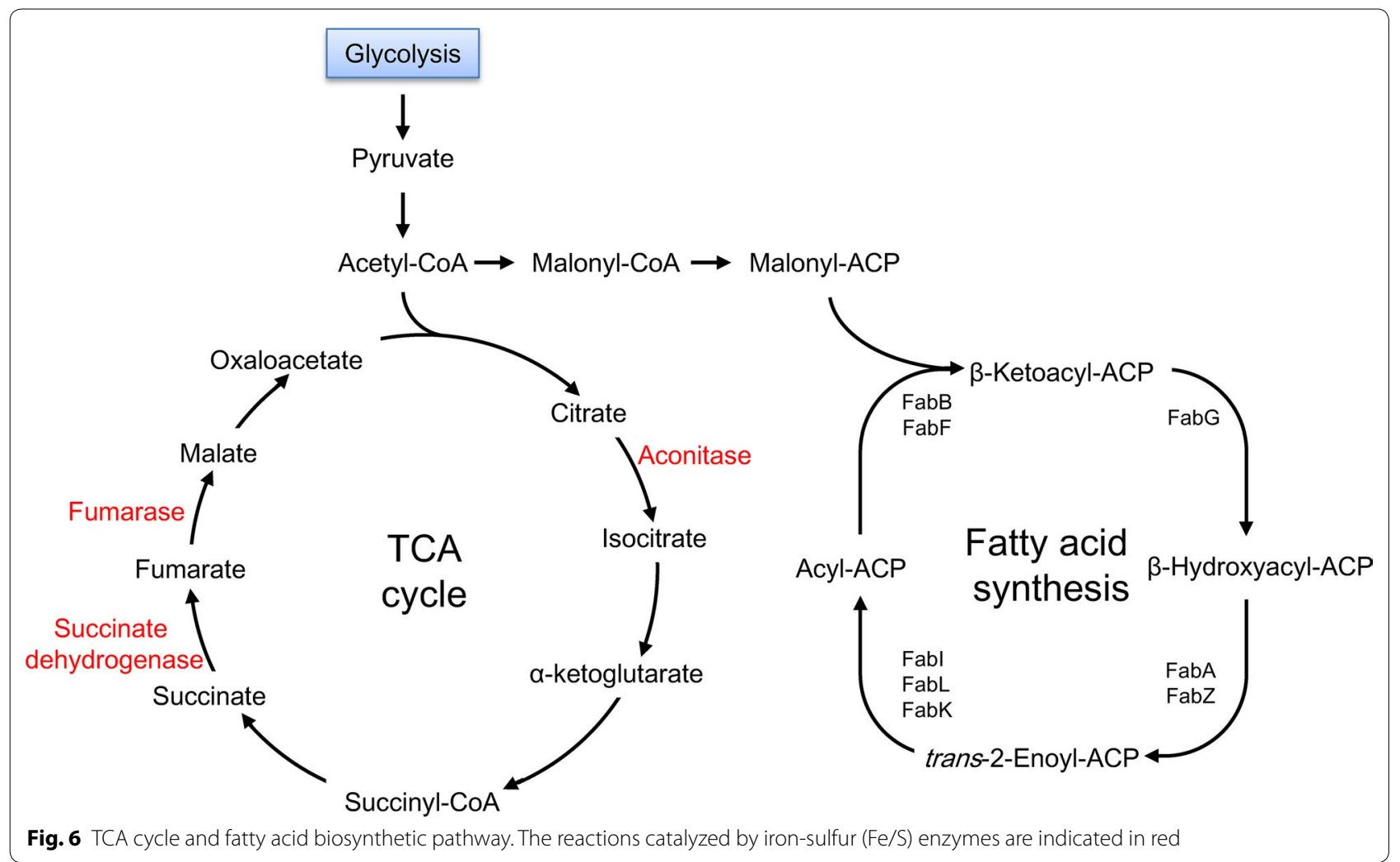

synthesizing high amounts of malonyl-CoA for the biosynthesis of related natural products.

\section{Conclusion}

A whole-cell biosensor was developed to rapidly report the intracellular malonyl-CoA level. The biosensor was successfully applied to screen a transposon insertion library of strain BW-WT and could identify targets related to the intracellular malonyl-CoA biosynthesis at a genome-wide scale. These selected mutant strains were verified to produce higher levels of free fatty acids, as well as higher titers of TAL or phloroglucinol when the corresponding synthase gene was introduced. Collectively, these results confirmed that the mutant strains exhibit higher intracellular malonyl-CoA biosynthetic capabilities and are applicable for natural product biosynthesis using malonyl-CoA as precursor.

\section{Methods}

\section{General}

DNA polymerase, T4 DNA ligase, and restriction endonucleases were purchased from Takara Bio Inc (Dalian, China). Oligonucleotides were synthesized by Life Technologies (Shanghai, China). TAL and triclosan was purchased from Sigma-Aldrich (St. Louis, USA).

\section{Plasmid construction}

The strains and plasmids used in this study are presented in Table 1 . The primers used for the plasmid construction are listed in Table 2. Plasmid pTn10 was constructed as follows. Fragment F1 containing genes tnp* encoding Tn10 transposase (Genbank Accession No. AF310136) under the control of $\mathrm{P}_{t a c}$ promoter, and mob gene encoding Mob protein (Genbank Accession No. NZ_LSAZ01000024) was synthesized by GENEWIZ (Suzhou, China). After digestion with $X b a \mathrm{I}$ and $X h o \mathrm{I}$, fragment F1 was ligated into the PCR product amplified with primers GEX-XhoI-fwd and GEX-XbaI-rev using plasmid pGEX-6P-1 (GE Healthcare) as template, resulting in plasmid pGEX-TM. Fragment F2 containing R6K replication origin was amplified with primers R6K-NotIfwd and R6K-overlap-rev using plasmid pAH156 [36] (Genbank Accession No. AY048737) as template. Fragment F3 containing IS10L, gene kan, and IS10R [37] was amplified using plasmid pSM04 [38] as template with primers IS-overlap-fwd and IS-SacII-rev. Fragment F2 and F3 were PCR-assembled with primers R6K-NotI-fwd and IS-SacII-rev, resulting in fragment F4. After digestion with NotI and SacII, fragment F4 was ligated into the PCR product amplified with primers lacI-SacII-fwd and amp-NotI-rev using plasmid pGEX-TM as template, 
Table 1 Plasmids and strains used in this study

\begin{tabular}{|c|c|c|}
\hline Strains and plasmids & Description & Source \\
\hline \multicolumn{3}{|l|}{ Plasmids } \\
\hline pS1 & Genes encoding AraC-TAL and 2-PS variant S1 under the control of promoter $\mathrm{P}_{\text {tac }} \cdot \mathrm{Amp}^{r}$ & This study \\
\hline pTn10 & Transposon Tn10, Kan & This study \\
\hline $\mathrm{pPhID}$ & Gene phID under the control of $\mathrm{P}_{\mathrm{BAD}}$, $\mathrm{Kan}^{r}$ & This study \\
\hline \multicolumn{3}{|l|}{ Strains } \\
\hline BW-WT & BW25113 ( $\triangle$ araC), with promoter $P_{B A D}$ controlled lacZ integrated & This study \\
\hline$\triangle \operatorname{rcs} A$ & BW25113 ( $\Delta$ rcsA) & This study \\
\hline$\triangle$ fhuA & BW25113 ( $\triangle$ fhuA) & This study \\
\hline$\triangle \operatorname{csg} A$ & BW25113 ( $\triangle \operatorname{csg} A)$ & This study \\
\hline$\triangle \operatorname{ton} B$ & BW25113 (AtonB) & This study \\
\hline
\end{tabular}

Table 2 Primers used in this study

\begin{tabular}{|c|c|}
\hline Primer name & Sequences $\left(5^{\prime}-3^{\prime}\right)$ \\
\hline GEX-Xhol-fwd & CGGCTCGAGTGACGATCTGCCTCGCGCGT \\
\hline GEX-Xbal-rev & TGCTCTAGATCACTGCCCGCTTTCCAGTC \\
\hline R6K-Notl-fwd & TAAGCGGCCGCCTAATTCCCATGTCAGCCGT \\
\hline R6K-overlap-rev & GACAAGATGTGTATCCACCTTAACTAAGATCCGGCCACGATGCGTCCGGC \\
\hline IS-overlap-fwd & ATCGTGGCCGGATCTTAGTTAAGGTGGATACACATCTTGTCATATGATCTACTAGAGCTGATCCTTCAAC \\
\hline IS-Sacll-rev & AAACCGCGGAGTTAAGGTGGATACACATCTTGTCATATGATCTTAGAAAAACTCATCGAGCA \\
\hline lacl-Sacll-fwd & AAACCGCGGTATTTTCTCCTTACGCATCT \\
\hline amp-Notl-rev & TAGGCGGCCGCTTACCAATGCTTAATCAGTG \\
\hline lacz-F & TTTAAGAAGGAGATATACATATGACCATGATTACGGATTC \\
\hline lacZ-R & TTATTTTTGACACCAGACCA \\
\hline$P_{B A D}-F$ & CCATAAGATTAGCGGATCCT \\
\hline$P_{B A D}-R$ & GAATCCGTAATCATGGTCATATGTATATCTCCTTCTTAAA \\
\hline pAH156- $\mathrm{P}_{\mathrm{BAD}}-\mathrm{F}$ & CTCTAGATAAGGAGGAAAAACTCGAGCCATAAGATTAGCGG \\
\hline pAH156-lacZ-R & CTCGGTACCCGGGGATCCGCTCTCGAGGTCGACGGTATCG \\
\hline lacZ-pAH156-F & CGATACCGTCGACCTCGAGAGCGGATCCCCGGGTACCGAG \\
\hline$P_{B A D}-p A H 156-R$ & CCGCTAATCTTATGGCTCGAGTTTTTCCTCCTTATCTAGAG \\
\hline kan-sp1 & TATCAGGACATAGCGTTGGCTACCCG \\
\hline kan-sp2 & CGGCGAATGGGCTGACCGCTTC \\
\hline kan-sp3 & GTGCTTTACGGTATCGCCGCTC \\
\hline sp-seq & CATCGCCTTCTATCGCCTTCTT \\
\hline AD1 & NGTCGASWGANAWGAA \\
\hline AD2 & TGWGNAGSANCASAGA \\
\hline AD3 & AGWGNAGWANCAWAGG \\
\hline AD4 & STTGNTASTNCTNTGC \\
\hline
\end{tabular}

Restriction sites are underlined

$\mathrm{N}, \mathrm{A}$ or $\mathrm{C}$ or $\mathrm{G}$ or $\mathrm{T} ; \mathrm{S}, \mathrm{G}$ or $\mathrm{C} ; \mathrm{M}, \mathrm{A}$ or $\mathrm{C} ; \mathrm{W}, \mathrm{A}$ or $\mathrm{T}$

resulting in plasmid pTn10. The gene encoding AraCTAL (P8 V, T24I, H80G, Y82L, H93R) [17] was synthesized by GENEWIZ (Beijing, China). After digested with $N d e \mathrm{I}$ and $\mathrm{XhoI}$, it was subsequently ligated into plasmid pSM02 [38], resulting in plasmid pSM02M. The mutated g2ps1 gene encoding the 2-PS variant S1 [17] was synthesized by GENEWIZ. It was digested with XhoI and EcoRI and subsequently ligated into plasmid pSM02M, resulting in plasmid pS1. The phlD gene (Genbank Accession No. EU554263.1) was synthesized by GENEWIZ (Beijing, 
China). The gene was digested with $\mathrm{NcoI}$ and $\mathrm{SacI}$ and subsequently ligated into plasmid pSM01, resulting in plasmid pPhlD.

\section{Strain construction}

Strains used in this study are listed in Table 1. Gene lac $Z$ was amplified using the genomic DNA of strain MG1655 as template with primers lacZ-F and lacZR. Promoter $P_{B A D}$ was amplified with primers $P_{B A D}-F$ and $\mathrm{P}_{\mathrm{BAD}}-\mathrm{R}$ using plasmid pSM04 [39] as template, The two PCR products were overlapped, and amplified again with primers pAH156- $\mathrm{P}_{\mathrm{BAD}}-\mathrm{F}$ and pAH156-lacZ-R, resulting in fragment $\mathrm{P}_{\mathrm{BAD}}$-lacZ. PCR was performed with prim-

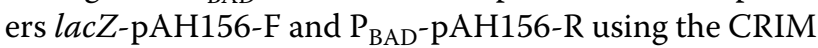
plasmid pAH156 [36] as template. The PCR product was assembled with fragment $\mathrm{P}_{\mathrm{BAD}}$-lacZ by Gibson Assembly [39]. The construct was then integrated into the chromosome of strain BW1A (strain BW25113 with gene araC deleted) [38], using helper plasmid pAH69 [36], resulting in strain BW-WT. The integration was verified by PCR. Deletion of $E$. coli chromosomal genes, rcs A, fhuA, csgA and $\operatorname{ton} B$ was carried out via P1 phage transduction using phage libraries of strain JW1935-1, JW0146-2, JW1025-1 and JW5195-1 (Keio collection) [40], and then the FRTflanked kan gene was removed using flipase-mediated recombination [41], resulting in strains $\triangle \operatorname{rcs} A, \triangle f h u A$, $\triangle \operatorname{csg} A$ and $\triangle \operatorname{ton} B$, respectively.

\section{Construction and screening of random transposon insertion library}

Strain BW-WT harboring plasmid pS1 carrying genes encoding AraC-TAL and the 2-PS variant S1 was transformed with plasmid pTn10, and then plated on LB agar containing $1 \mathrm{mM}$ IPTG. After incubation at $37{ }^{\circ} \mathrm{C}$ for $16 \mathrm{~h}$, the darkest blue colonies (by the eye) were selected and cultured in $3 \mathrm{~mL} \mathrm{LB}$ for LacZ activity assay and TAL quantification using HPLC.

To identify the location of the transposon insertion in the chromosome, the thermal asymetric interlaced (TAIL)-PCR was conducted as described [42, 43]. Strains exhibiting increased shikimic acid productions were cultured and harvested to isolate genomic DNA. $100 \mathrm{ng}$ of the genomic DNA was used as template for TAIL-PCR. Genomic sequences flanking the transposon were amplified with a mixture of four arbitrary degenerate (AD) primers (AD1-4), plus the specific primer inside the kan gene, kan-SP1, kan-SP2 and kan-SP3, individually. Three rounds of TAIL-PCR cycling were performed. The tertiary TAIL-PCR product was purified and sequenced using primer sp-seq. The sequence obtained was blasted in the database of $E$. coli K-12 strain W3110 (http:// ecocyc.org/) to identify the location of the transposon insertion in the chromosome. The location was further verified using PCR with primers kan-SP3 plus the primer designed according to the chromosome DNA sequence close to the insertion point.

\section{$\beta$-Galactosidase activity assay}

$\beta$-Galactosidase activity was assayed as described by Miller [44], with some modifications. The reaction mixture was prepared by addition of $650 \mu \mathrm{L}$ buffer $\mathrm{Z}$, $40 \mu \mathrm{L}$ of $12 \mathrm{mM}$ 2-nitrophenyl- $\beta$-D-galactopyranoside $(o \mathrm{NPG})$ and $10 \mu \mathrm{L}$ of the cell lysate. After incubation at $37{ }^{\circ} \mathrm{C}$ for $10 \mathrm{~min}$, the reaction was terminated by the addition of $185 \mu \mathrm{L}$ of $1 \mathrm{M}$ sodium carbonate. The absorbance at $420 \mathrm{~nm}$ was measured with a SynergyMx Multi-Mode Microplate Reader (BioTek, Vermont, USA). $\beta$-Galactosidase activity in Miller units was calculated as $\left(1000 \times \mathrm{OD}_{420}\right) /\left(\mathrm{T} \times \mathrm{V} \times \mathrm{OD}_{600}\right)$, where $\mathrm{T}$ represents the reaction time (minute) and $\mathrm{V}$ represents the volume of cell lysate used in the assay $(\mathrm{mL})$.

\section{HPLC quantification}

The concentration of TAL and phloroglucinol in the cell-free supernatant were measured by HPLC using a Shimadzu LC-20A system equipped with a photodiode array detector (Shimadzu Corp., Kyoto, Japan) operating at $280 \mathrm{~nm}$ (for TAL) or $265 \mathrm{~nm}$ (for phluroglucinol). Separation was achieved using a Waters Symmetry C18 column $(250 \times 4.6 \mathrm{~mm}, 5 \mu \mathrm{m})$ (Waters, USA) working at $30{ }^{\circ} \mathrm{C}$ with the mobile phase of $20 \%$ acetonitrile (containing $0.1 \%$ acetic acid) at a flow rate of $0.6 \mathrm{~mL} / \mathrm{min}$ (for TAL) and the mobile phase of $10 \%$ methanol at a flow rate of $0.6 \mathrm{~mL} / \mathrm{min}$ (for phloroglucinol).

\section{GC-MS identification of free fatty acids}

Fatty acids were extracted from $400 \mu \mathrm{L}$ of acidified culture with ethyl acetate and esterified with ethanol. Fatty ethyl esters were extracted with hexane and run on an HP 5890 chromatograph with FID detector using a DB-5 capillary column (length, $30 \mathrm{~m}$; inner diameter, $0.25 \mathrm{~mm}$; film thickness, $0.25 \mu \mathrm{m}$; J\&W Scientific, Folsom, USA). The temperature program ran from 170 to $300{ }^{\circ} \mathrm{C}$ with an initial and final holding time of $2 \mathrm{~min}$ and a rate of $10^{\circ} \mathrm{C} /$ min. The injector and detector temperatures were 240 and $300{ }^{\circ} \mathrm{C}$, respectively. Helium was the carrier gas, with a linear flow velocity of $40 \mathrm{~mL} / \mathrm{min}$ at $100^{\circ} \mathrm{C}$.

\section{Additional file}

Additional file 1: Figure S1. Dark blue clones selected from the transposon insertion library grown on LB agar supplemented with X-GAL, together with the wild-type strain. 


\section{Abbreviations}

ACC: acetyl-CoA carboxylase; DTPA: diethylene triaminepentaacetic acid; TAL: triacetic acid lactone; TCA: tricarboxylic acid; X-GAL: 5-bromo-4-chloro-3indolyl $\beta$-D-galactopyranoside.

\section{Authors' contributions}

$\mathrm{HL}, \mathrm{WC}$ and RJ conducted the experiments and analyzed the data. J-MJ and S-YT designed the experiments and prepared the manuscript. All authors read and approved the final manuscript.

\section{Author details}

${ }^{1}$ CAS Key Laboratory of Microbial Physiological and Metabolic Engineering, State Key Laboratory of Microbial Resources, Institute of Microbiology, Chinese Academy of Sciences, Beijing, China. ${ }^{2}$ Beijing Key Laboratory of Plant Resources Research and Development, Beijing Technology and Business University, Beijing, China. ${ }^{3}$ University of Chinese Academy of Sciences, Beijing, China.

\section{Acknowledgements}

This work was supported by Ministry of Science and Technology of China Grant 2013CB734003, the National Natural Science Foundation of China (Grant No. 21472234, 31501037 and 31160017), and the CAS/SAFEA International Partnership Program for Creative Research Teams.

\section{Competing interests}

The authors declare that they have no competing interests.

\section{Availability of data and materials}

All data generated or analyzed in this study are included in this manuscript.

\section{Consent for publication}

All of the authors agree with the submission.

Ethics approval and consent to participate

Not applicable.

\section{Funding}

Indicated in the Acknowledgments.

\section{Publisher's Note}

Springer Nature remains neutral with regard to jurisdictional claims in published maps and institutional affiliations.

Received: 18 April 2017 Accepted: 24 October 2017

Published online: 02 November 2017

\section{References}

1. Kładna A, Michalska T, Berczyński P, Kruk I, Aboul-Enein HY. Evaluation of the antioxidant activity of tetracycline antibiotics in vitro. Luminescence. 2012;27:249-55

2. Lam ET, Goel S, Schaaf LJ, Cropp GF, Hannah AL, Zhou Y, Mccracken B, Haley BI, Johnson RG, Mani S. Phase I dose escalation study of KOS-1584, a novel epothilone, inpatients with advanced solid tumors. Cancer Chemother Pharmacol. 2012;69:523-31.

3. Gatto GJ, Boyne MT, Kelleher NL, Walsh CT. Biosynthesis of pipecolic acid by RapL, a lysine cyclodeaminase encoded in the rapamycin gene cluster. J Am Chem Soc. 2006:128:3838-47.

4. Malaiyandi V, Houle MC, Skotnickigrant S. Airborne allergic contact dermatitis from tylosin in pharmacy compounders and cross-sensitization to macrolide antibiotics. Dermatitis. 2012;23:227-30.

5. Khosla C, Gokhale RS, Jacobsen JR, Cane DE. Tolerance and specificity of polyketide synthases. Annu Rev Biochem. 1999;68:219-53.

6. Kallscheuer N, Vogt M, Marienhagen J. A novel synthetic pathway enables microbial production of polyphenols independent from the endogenous aromatic amino acid metabolism. ACS Synth Biol. 2016;6:410-5.

7. Ahmadi MK, Pfeifer BA. Recent progress in therapeutic natural product biosynthesis using Escherichia coli. Curr Opin Biotechnol. 2016;42:7-12.
8. Leonard E, Lim KH, Saw PN, Koffas MA. Engineering central metabolic pathways for high-level flavonoid production in Escherichia coli. Appl Environ Microbiol. 2007;73:3877-86.

9. Zha W, Rubin-Pitel SB, Shao Z, Zhao H. Improving cellular malonylCoA level in Escherichia coli via metabolic engineering. Metab Eng. 2009;11:192-8.

10. Mothes GR, Rivera IS, Babel W. Competition between beta-ketothiolase and citrate synthase during poly(beta-hydroxybutyrate) synthesis in Methylobacterium rhodesianum. Arch Microbiol. 1996;166:405-10.

11. Munday MR, Hemingway CJ. The regulation of acetyl-CoA carboxylasea potential target for the action of hypolipidemic agents. Adv Enzyme Regul. 1999;39:205-34.

12. Davis MS, Solbiati J, Cronan JE Jr. Overproduction of acetyl-CoA carboxylase activity increases the rate of fatty acid biosynthesis in Escherichia coli. J Biol Chem. 2000;275:28593-8.

13. Lennen RM, Pfleger BF. Engineering Escherichia coli to synthesize free fatty acids. Trends Biotechnol. 2012;30:659-67.

14. Rathnasingh C, Raj SM, Lee Y, Catherine C, Ashok S, Park S. Production of 3-hydroxypropionic acid via malonyl-CoA pathway using recombinant Escherichia coli strains. J Biotechnol. 2011;157:633-40.

15. Sarkar S, Dasgupta UB, Summers WC. Error-prone mutagenesis detected in mammalian cells by a shuttle vector containing the supf gene of Escherichia coli. Mol Cell Biol. 1984;4:2227-30.

16. Gao L, Chiou W, Tang H, Cheng XH, Camp HS, Burns DJ. Simultaneous quantification of malonyl-CoA and several other short-chain acyl-CoAs in animal tissues by ion-pairing reversed-phase HPLC/MS. J Chromatogr B. 2007:853:303-13.

17. Tang SY, Qian S, Akinterinwa O, Frei CS, Gredell JA, Cirino PC. Screening for enhanced triacetic acid lactone production by recombinant Escherichia coli expressing a designed triacetic acid lactone reporter. J Am Chem Soc 2013:135:10099-103.

18. Mcmurry LM, Oethinger M, Levy SB. Triclosan targets lipid synthesis Nature. 1998:394:531-2.

19. Surolia N, Surolia A. Triclosan offers protection against blood stages of malaria by inhibiting enoyl-ACP reductase of Plasmodium falciparum. Nat Med. 2001;7:167-73.

20. Locher KP, Rees B, Koebnik R, Mitschler A, Moulinier L, Rosenbusch JP, Moras D. Transmembrane signaling across the ligand-gated FhuA receptor: crystal structures of free and ferrichrome-bound states reveal allosteric changes. Cell. 1998:95:771-8.

21. James K, Hancock MA, Moreau V, Molina F, Coulton J. TonB induces conformational changes in surface-exposed loops of FhuA, outer membrane receptor of Escherichia coli. Protein Sci. 2008;17:1679-88.

22. Keyer K, Imlay JA. Superoxide accelerates DNA damage by elevating freeiron levels. Proc Natl Acad Sci USA. 1996;93:13635-40.

23. Zha W, Rubinpitel SB, Zhao H. Characterization of the substrate specificity of PhID, a type III polyketide synthase from Pseudomonas fluorescens. J Biol Chem. 2006;281:32036

24. Flint DH, Emptage MH, Guest JR. Fumarase A from Escherichia coli-purification and characterization as an iron sulfur cluster containing enzyme. Biochemistry. 1992;31:10331-7.

25. Tang Y, Guest JR. Direct evidence for mRNA binding and post-transcriptional regulation by Escherichia coli aconitases. Microbiology. 1999;145:3069-79.

26. Masse E, Gottesman S. A small RNA regulates the expression of genes involved in iron metabolism in Escherichia coli. Proc Natl Acad Sci USA. 2002;99:4620-5.

27. Cecchini G, Maklashina E, Yankovskaya V, Iverson TM, Iwata S. Variation in proton donor/acceptor pathways in succinate:quinone oxidoreductases. FEBS Lett. 2003;545:31-8.

28. Yankovskaya V, Horsefield R, Tornroth S, Luna-Chavez C, Miyoshi H, Leger C, Byrne B, Cecchini G, Iwata S. Architecture of succinate dehydrogenase and reactive oxygen species generation. Science. 2003;299:700-4.

29. Ebel W, Trempy JE. Escherichia coli RcsA, a positive activator of colanic acid capsular polysaccharide synthesis, functions to activate its own expression. J Bacteriol. 1999;181:577-84

30. Schujman GE, Guerin M, Buschiazzo A, Schaeffer F, Llarrull LI, Reh G, Vila AJ, Alzari PM, de Mendoza D. Structural basis of lipid biosynthesis regulation in gram-positive bacteria. EMBO J. 2006:25:4074-83.

31. Li SJ, Si T, Wang M, Zhao HM. Development of a synthetic malonyl-CoA sensor in Saccharomyces cerevisiae for intracellular metabolite monitoring and genetic screening. ACS Synth Biol. 2015;4:1308-15. 
32. Xu P, Li LY, Zhang FM, Stephanopoulos G, Koffas M. Improving fatty acids production by engineering dynamic pathway regulation and metabolic control. Proc Natl Acad Sci USA. 2014;111:11299-304.

33. David F, Nielsen J, Siewers V. Flux control at the malonyl-CoA node through hierarchical dynamic pathway regulation in Saccharomyces cerevisiae. ACS Synth Biol. 2016;5:224-33.

34. Liu D, Xiao Y, Evans BS, Zhang FZ. Negative feedback regulation of fatty acid production based on a malonyl-CoA sensor-actuator. ACS Synth Biol. 2015:4:132-40.

35. Xu P, Wang WY, Li LY, Bhan N, Zhang FM, Koffas MAG. Design and kinetic analysis of a hybrid promoter-regulator system for malonyl-CoA sensing in Escherichia coli. ACS Chem Biol. 2014;9:451-8.

36. Haldimann A, Wanner BL. Conditional replication, integration, excision, and retrieval plasmid-host systems for gene structure-function studies of bacteria. J Bacteriol. 2001;183:6384-93.

37. Wright D, DeBeaux A, Shi RH, Doherty AJ, Harrison L. Characterization of the roles of the catalytic domains of Mycobacterium tuberculosis ligase D in Ku-dependent error-prone DNA end joining. Mutagenesis. 2010;25:473-81

38. Chen W, Zhang S, Jiang P, Yao J, He Y, Chen L, Gui X, Dong Z, Tang SY. Design of an ectoine-responsive AraC mutant and its application in metabolic engineering of ectoine biosynthesis. Metab Eng. 2015;30:149-55.
39. Gibson DG, Young L, Chuang RY, Venter JC, Smith HO. Enzymatic assembly of DNA molecules up to several hundred kilobases. Nat Methods. 2009;6:343-5.

40. Baba T, Ara T, Hasegawa M, Takai Y, Okumura Y, Baba M, Datsenko KA, Tomita M, Wanner BL, Mori H. Construction of Escherichia coli K-12 inframe, single-gene knockout mutants: the Keio collection. Mol Syst Biol. 2006;2006(2):0008.

41. Datsenko KA, Wanner BL. One-step inactivation of chromosomal genes in Escherichia coli K-12 using PCR products. Proc Natl Acad Sci USA. 2000;97:6640-5.

42. Liu YG, Whittier RF. Thermal asymmetric interlaced PCR-automatable amplification and sequencing of insert end fragments from P1 and YAC clones for chromosome walking. Genomics. 1995;25:674-81.

43. Sessions A, Burke E, Presting G, Aux G, McElver J, Patton D, Dietrich B, Ho P, Bacwaden J, Ko C, Clarke JD, Cotton D, Bullis D, Snell J, Miguel T, Hutchison D, Kimmerly B, Mitzel T, Katagiri F, Glazebrook J, Law M, Goff SA. A high-throughput Arabidopsis reverse genetics system. Plant Cell. 2002;14:2985-94.

44. Rd MC, Martinat MA, Hyman LE. Assessment of aryl hydrocarbon recepto complex interactions using pBEVY plasmids: expressionvectors with bidirectional promoters for use in Saccharomyces cerevisiae. Nucleic Acids Res. 1998;26:3577.

\section{Submit your next manuscript to BioMed Central and we will help you at every step:}

- We accept pre-submission inquiries

- Our selector tool helps you to find the most relevant journal

- We provide round the clock customer support

- Convenient online submission

- Thorough peer review

- Inclusion in PubMed and all major indexing services

- Maximum visibility for your research

Submit your manuscript at www.biomedcentral.com/submit 